DE

M E D I C I N A

T R O P I C A L

$\mathrm{DE}$

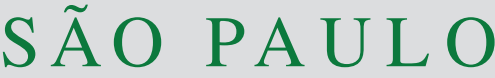

JOURNAL OF THE SÃO PAULO INSTITUTE OF TROPICAL MEDICINE

1 Universidade Federal da Grande Dourados, Laboratório de Pesquisa em Ciências da Saúde, Dourados, Mato Grosso do Sul, Brazil

${ }^{2}$ Fundação Oswaldo Cruz, Campo Grande, Mato Grosso do Sul, Brazil

${ }^{3}$ Universidade Federal de Mato Grosso do Sul, Faculdade de Medicina, Campo Grande, Mato Grosso do Sul, Brazil

Correspondence to: Simone Simionatto Universidade Federal da Grande Dourados, Laboratório de Pesquisa em Ciências da Saúde, Rodovia Dourados-Itahum, km 12, Cidade Universitária, CEP 79804970, Dourados, MS, Brazil

Tel: +55 6734102225

Fax: +556734102256

E-mail: simonesimionatto@ufgd.edu.br

Received: 8 August 2020

Accepted: 18 November 2020

\section{Epidemiological study in Brazilian women highlights that syphilis remains a public health problem}

\author{
Marcelo dos Santos Barbosa', Leticya Aparecida de Lima ${ }^{1}$, Suzana Meira \\ Ribeiro1, Julio Croda ${ }^{2,3}$, Júlio Henrique Ferreira de Sá Queiroz', Lais \\ Gonçalves Ortolani' ${ }^{1}$, Fábio Juliano Negrão ${ }^{1}{ }^{1}$, Elaine Costa Souza1, Kesia \\ Esther da Silva1, Ronaldo Omizolo de Souza1, Simone Simionatto ${ }^{(1}$
}

\section{ABSTRACT}

Syphilis, an infectious disease considered a global public health concern, can cause stillbirths and neonatal deaths. This highlights the importance of continuous surveillance studies among women of reproductive age. A cross-sectional study was carried out to analyze the prevalence and risk factors associated with Treponema pallidum infection in women assisted by primary health care units in Dourados, a city located in Mato Grosso do Sul State, Brazil, which borders Paraguay. A questionnaire was applied to a population-based sample, blood samples were collected for syphilis testing and multivariable analyses were performed to screen associations with $T$. pallidum infection. The prevalence of $T$. pallidum infection was $6.04 \%$. Bivariate analysis showed that women referring multiple sexual partners $\left(\chi^{2}: 6.97[\mathrm{p}=0.014]\right)$, income less 2 minimal wages $\left(\chi^{2}: 15.93[\mathrm{p}=0.003]\right)$, who did not have high school $\left(\chi^{2}: 12.64[\mathrm{p}=0.005]\right)$, and reporting history of STIs $\left(\chi^{2}: 7.30[\mathrm{p}=0.018]\right)$ are more likely to have syphilis. In the multivariate analysis, a highest prevalence ratio was observed in women with income less than 2 minimal wages (PR: 0.96 [95\% CI: 0.85 - 0.97]), and who did not have high school (PR: 0.94 [95\% CI: 0.90 - 0.98]). In addition, 80\% of the women reported irregular use of condoms and $63.89 \%$ declared having sexual intercourses with multiple partners, which creates more opportunities for the transmission of the infection. These results highlight the need for healthcare systems to implement initiatives to monitor syphilis screening and the commitment of patients and their sexual partners to the treatment in order to achieve a decrease of new cases.

KEYWORDS: Risk factors. Syphilis. Women. Primary health.

\section{INTRODUCTION}

Syphilis is an infectious disease caused by the bacterium Treponema pallidum subspecies pallidum ${ }^{1}$. Risky sexual behaviors are a frequent cause of this disease. Infected mothers can also transmit syphilis to their offspring during pregnancy or childbirth. Congenital syphilis is often fatal and can result in prematurity, low birth weight and congenital deformities ${ }^{2}$. This disease represents a global concern, as it can cause neurological, cardiovascular and congenital complications. Syphilis can also facilitate HIV transmission, leading to increased rates of adverse outcomes ${ }^{1}$.

Acquired syphilis refers to infection by T. pallidum acquired through sexual intercourse, intimate contact or through sharing objects. Syphilis is a public health problem, especially in pregnant women, due to the risk of transmission to the fetus causing neurosyphilis, a frequent cause of death due to syphilis ${ }^{3,4}$. The number 
of cases of syphilis in women has grown in some regions of the world ${ }^{5,6}$. In Brazil, the number of acquired syphilis increased 28\% between 2017 and 2018. The prevalence rates of acquired syphilis more than tripled, being $26.66 / 100,000$ inhabitants in 2013 to $81.40 / 100,000$ in 2017; the cases in pregnant women more than doubled in the same period, with a rate of 7.11/100,000 inhabitants in 2013 to 16.85/100,000 in 2017 ${ }^{7}$. Mato Grosso do Sul State recorded the second highest detection rate (163.0 cases/ 100,000 inhabitants), a higher number than the national average rate $(75.8 / 100,000 \text { inhabitants })^{8}$. Many countries, including Brazil, are committed to reducing syphilis ${ }^{9,10}$. Thus, monitoring T. pallidum can contribute to the strategic planning for a better prevention and control of this infection.

Dourados, a city in Mato Grosso do Sul, a State located in Midwest Brazil that borders Paraguay and Bolivia, with a population of 2.5 million people is subjected to some factors that may expose the population to a higher risk of sexually transmitted infections (STIs), such as the proximity to an international border, illegal drugs trafficking, as well as the presence of indigenous and prison populations. Therefore, epidemiological studies in these locations could be useful to strengthen actions to prevent, detect and treat syphilis. Furthermore, it could lead to surveillance actions involving binational efforts. The purpose of this study was to determine the prevalence of T. pallidum infection and associated variables in women over 18 years old, attending primary health units in the city.

\section{MATERIAL AND METHODS}

\section{Type of study and sample size calculation}

A cross-sectional study was carried out from October 2015 to August 2016, in women attending primary health care units of Dourados, the second largest city of Mato Grosso do Sul State, with an estimated population of 222,949 inhabitants ${ }^{11}$. According to the Notifiable Diseases Information System (SINAN, Brazil), Dourados has 36 primary health units, 28 of them located in urban areas, divided in four regions (North, South, East, West). The sample size was calculated using a national average prevalence of $3 \%$ for syphilis ${ }^{7}$, with a variation of $1 \%$, considering the accuracy of $1.50 \%$ and confidence level of $95 \%$, resulting in a minimum sample of 497 women.

\section{Study participants}

The present study included women who were 18 years old or more, who attended primary health care units and signed an informed consent form. Women under 18 years old or those who refused to sign the consent form were excluded. Sample collection and randomization was performed using the cluster determined by the primary health care unit according to its location, divided by regions, considering the number of people served by it. Thus, the city was divided into eight clusters, covering a primary health care unit, being: PHU Vila Rosa, PHU Cabeceira Alegre, PHU Piratininga, PHU Joquei, PHU Parque do Lago II, PHU Vila Matos, PHU Agua Boa and PHU Seleta (Figure 1). The sample collection was performed from October 2015 to August 2016. Women who sought the primary health care unit were invited to participate in the study, according to a numeric balance of each region to comprise a heterogeneous population representative of the city.

\section{Data and blood collection}

Each participant underwent an interview in which a standardized questionnaire was used. The following variables were obtained during the interview: age, partner status (fixed partner for more than 5 years), education (illiterate, basic education, high school or graduation), drug use, risky sexual behavioral (sex with a drug user, sex with an injectable drug, sexual partner whit HIV), STI history or other parameters indicative of sexually-transmitted infection (HIV positive, syphilis positive, vaginal discharge, wart in the genital region, genital ulcer disease, hands and feet ulcer disease), blood transfusion, tattoos, piercings, previous surgery, time served in prisons, and self-reported mental illness. The participant's skin color (white, black, Asian, or mixed) was self-reported. Categorical variables were represented as "Yes" or "No", and numerical variables were categorized later.

After appropriate antisepsis, a $10 \mathrm{~mL}$ sample of peripheral venous blood was obtained using a vacuum tube system. The sample was sent to the Health Sciences Laboratory, at the Federal University of Grande Dourados, where it was processed to obtain serum samples stored at $-20{ }^{\circ} \mathrm{C}$ for the serological assays.

\section{Serological testing}

The serological diagnosis was determined by the Enzyme-Linked Immunosorbent Assay (ELISA) (ICE*Syphilis, DiaSorin, Saluggia, Italy) following the manufacturer's instructions. ELISA-reactive samples were serially diluted and titrated to detect anticardiolipin antibodies using the Venereal Disease Research Laboratory (VDRL) test (Abbott Murex, Dartford, UK). All tests were performed at the Health Sciences Research Laboratory 


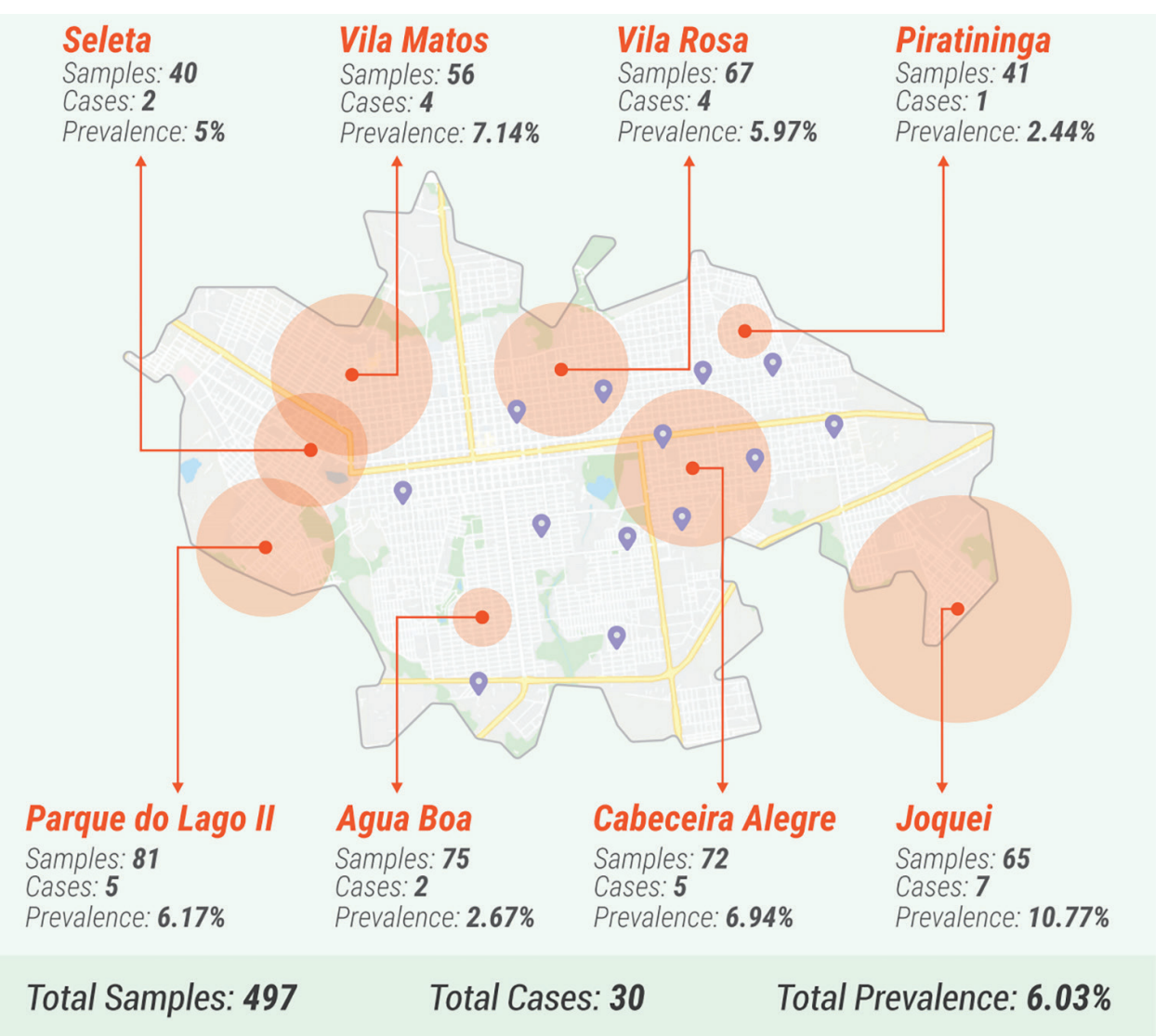

Figure 1 - Primary health care unities in urban areas from Dourados, Mato Grosso do Sul State, sample collection locations, prevalence of syphilis per health care unit evaluated. Blue dots are the primary health care units that were not included in this study and the red dots are the ones included.

of Universidade Federal da Grande Dourados. A team of previously trained health professionals performed the interviews, data collection and tests. Patients were considered to have syphilis when they were reagent to treponemal and non-treponemal tests according to reference intervals recommended by the manufacturers. All subjects received the results of their serological tests individually and a specialist in infectious diseases physician prescribed appropriate treatment to those with results indicating acquired syphilis. All new cases of syphilis identified were reported to the Notifiable Disease database (Sistema de Informacao de Agravos de Notificacao, SINAN).

\section{Statistical analysis}

Data based on questionnaires and biological test results were recorded, double-checked and inserted into the online Research Electronic Data Capture (REDCap) database. The SAS version 9.2 (SAS Institute Cary, North Carolina, USA) was used to analyze the univariate and multivariate models. Descriptive analyzes of sociodemographic, behavioral characteristics and frequency of syphilis were performed. The prevalence of $T$. pallidum infection was expressed as the percentage among the screened women and the Clopper-Pearson exact test was used to calculate the binomial confidence interval. These analyzes were performed using the SPSS version 20 (IBM, Armonk, NY, USA). The dependent variable was to have or not syphilis.

The independent variables were analyzed and received appropriate treatment. A descriptive analysis of independent variables was performed, in which measures of central tendency were used for quantitative variables (age) and proportions (\%) and $95 \%$ confidence intervals for categorical variables. Then, a bivariate analysis was performed with Pearson's chi-square test and Fisher's exact test for categorical variables. In the adjusted analysis, Poisson regression was used through a robust variance estimator and logarithmic linking function, and results were expressed in prevalence ratios (PR) and confidence intervals (CI). The variables with $p<0.2$ in the bivariate analysis using the $\chi^{2}$ test were inserted into the regression model, the variables that were not dichotomous were regrouped (Education [0. None or low; 1. Medium or high] and income [0. $<2$ wages; $1 .>2$ wages]). Multicollinearity analysis (VIF $<2$ and tolerance $>0.6$ ) was performed. For the quality of the adjustment, the likelihood test, Wald's hypothesis test 
and residual analysis (X2 (3) = 19,779; p<0.001) were used. The variables remained in the model if $\mathrm{p}<0.05$.

\section{Ethical approval}

This study complied with the requirements of the Research Ethics Committee of the Federal University of Grande Dourados ( $N^{\circ}$ 1.372.627/2015). All eligible participants provided written informed consent before taking part in the study. The serological test results were reported directly to the women by a medical doctor who also provided further orientation for the treatment.

\section{RESULTS}

\section{Socio-demographic factors and risk behaviors}

In this study, 513 women were invited to participate and 497 (96.88\%) agreed with the interview and provided blood samples. The socioeconomic profile of these women was: black or of mixed ethnicity women (51\%), low educational level $(49.5 \%)$, with an income below a minimum wage (39\%), 81\% declared to be in a stable relationship for more than 5 years and $58.75 \%$ reported that they did not use a condom during sexual intercourse (Table 1).

Table 1 - Socio-demographic, risk behaviors and prevalence of syphilis in 497 women attended in the primary health care system.

\begin{tabular}{|c|c|c|c|c|c|c|c|}
\hline Variable & $\mathrm{N}$ & $(\%)$ & Syphilis & $(\%)$ & $95 \% \mathrm{Cl}$ & $\chi^{2}$ & $p$-value \\
\hline \multicolumn{8}{|l|}{ Sociodemographic characteristics } \\
\hline \multicolumn{8}{|l|}{ Age, years, mean ( $\pm S D$ ) } \\
\hline $41.85(13.94)$ & 497 & $(100)$ & 30 & $(6.04)$ & $4.01-8.51$ & & \\
\hline Family Basic Health Unities & & & & & & 5.30 & 0.622 \\
\hline Vila Rosa & 67 & $(13.48)$ & 4 & $(5.97)$ & $1.65-14.59$ & & \\
\hline Cabeceira Alegre & 72 & $(14.48)$ & 5 & $(6.94)$ & $2.29-15.47$ & & \\
\hline Piratininga & 41 & $(8.24)$ & 1 & $(2.44)$ & $0.00-12.86$ & & \\
\hline Joquei & 65 & $(13.07)$ & 7 & $(10.77)$ & $4.44-20.94$ & & \\
\hline Parque do Lago II & 81 & $(16.29)$ & 5 & $(6.17)$ & $2.03-13.82$ & & \\
\hline Vila Matos & 56 & $(11.26)$ & 4 & (7.14) & $1.98-17.29$ & & \\
\hline Agua Boa & 75 & (15.09) & 2 & $(2.67)$ & $0.32-9.30$ & & \\
\hline Seleta & 40 & $(8.04)$ & 2 & $(5.00)$ & $0.61-16.92$ & & \\
\hline Educational level & & & & & & 12.64 & 0.005 \\
\hline Illiterate & 23 & $(4.62)$ & 3 & $(13.04)$ & $2.78-33.59$ & & \\
\hline Basic education & 228 & $(45.87)$ & 21 & $(9.21)$ & $5.79-13.73$ & & \\
\hline High school & 178 & $(35.81)$ & 6 & (3.37) & $1.25-7.19$ & & \\
\hline Graduation & 68 & $(13.68)$ & 0 & (0) & 0 & & \\
\hline Ethnicity & & & & & & 2.28 & 0.516 \\
\hline White & 235 & $(47.38)$ & 14 & $(5.96)$ & $3.29-9.79$ & & \\
\hline Black & 38 & $(7.66)$ & 4 & $(10.53)$ & $2.94-24.80$ & & \\
\hline Asian & 8 & $(1.61)$ & 1 & $(12.50)$ & $0.32-52.65$ & & \\
\hline Mixed Black and White & 216 & $(43.35)$ & 11 & $(5.12)$ & $2.58-8.97$ & & \\
\hline Occupation & & & & & & 1.28 & 0.732 \\
\hline Housewife & 170 & $(34.20)$ & 11 & $(6.47)$ & $3.27-11.28$ & & \\
\hline Cleaning lady & 19 & $(3.82)$ & 0 & (0) & 0 & & \\
\hline Student & 17 & $(3.42)$ & 1 & $(5.88)$ & $0.15-28.69$ & & \\
\hline Other jobs & 291 & $(58.55)$ & 18 & $(6.19)$ & $3.71-9.60$ & & \\
\hline \multicolumn{8}{|l|}{ Income (Minimal wage) } \\
\hline None & 143 & $(28.77)$ & 8 & $(5.59)$ & $2.45-10.73$ & & \\
\hline One or less & 51 & $(10.26)$ & 2 & (3.92) & $0.48-13.46$ & & \\
\hline Between one and two & 136 & $(27.36)$ & 17 & $(12.50)$ & $7.45-19.26$ & & \\
\hline
\end{tabular}


Table 1 - Socio-demographic, risk behaviors and prevalence of syphilis in 497 women attended in the primary health care system (cont.)

\begin{tabular}{|c|c|c|c|c|c|c|c|c|}
\hline Variable & & $\mathrm{N}$ & $(\%)$ & Syphilis & $(\%)$ & $95 \% \mathrm{Cl}$ & $\chi^{2}$ & $p$-value \\
\hline & Between two and three & 142 & $(28.57)$ & 3 & $(2.11)$ & $0.44-6.05$ & & \\
\hline & Three or more & 25 & $(5.03)$ & 0 & $(0)$ & 0 & & \\
\hline \multicolumn{9}{|c|}{ Sexual and behavioral history } \\
\hline & Stable partner & 405 & $(81.89)$ & 19 & $(4.67)$ & $2.83-7.17$ & - & - \\
\hline & Multiple sexual partners & 92 & $(18.11)$ & 11 & $(11.96)$ & $6.12-20.39$ & 6.97 & $0.014^{*}$ \\
\hline & History of STI(s) & 37 & $(7.64)$ & 6 & $(16.22)$ & $6.19-32.01$ & 7.30 & $0.018^{*}$ \\
\hline & HIV positive & 4 & $(0.81)$ & 0 & (0) & 0 & - & - \\
\hline & Syphilis positive & 5 & $(1.06)$ & 5 & $(100)$ & $47.82-100$ & - & - \\
\hline & Vaginal discharge & 293 & $(58.95)$ & 17 & $(5.80)$ & $3.42-9.13$ & - & - \\
\hline & Wart in the genital region & 55 & $(11.07)$ & 3 & $(5.45)$ & $1.14-15.12$ & - & - \\
\hline & Genital ulcer disease & 62 & $(12.47)$ & 8 & $(12.90)$ & $5.74-23.85$ & 5.88 & $0.391^{*}$ \\
\hline & Hands and feet ulcer disease & 6 & $(1.21)$ & 1 & $(16.67)$ & $0.42-64.12$ & 1.21 & $0.313^{*}$ \\
\hline & Sex with a drug user & 36 & $(7.24)$ & 1 & $(2.78)$ & $0.00-14.53$ & - & - \\
\hline & Sex with an injectable drug & 9 & $(1.81)$ & 0 & (0) & 0 & - & - \\
\hline & Sexual partner whit HIV & 2 & $(0.45)$ & 0 & $(0)$ & 0 & - & - \\
\hline \multicolumn{9}{|c|}{ Sexual preference } \\
\hline & Heterosexual & 495 & $(99.60)$ & 30 & $(6.06)$ & $4.13-8.54$ & - & - \\
\hline & Homosexual & 2 & $(0.4)$ & 0 & (0) & 0 & - & - \\
\hline
\end{tabular}

\section{Condom use}

All women

$0.20 \quad 0.671$

\begin{tabular}{lccccccc} 
Always & 95 & $(19.11)$ & 6 & $(6.32)$ & $2.35-13.24$ \\
Sometimes & 110 & $(22.13)$ & 5 & $(4.55)$ & $1.49-10.29$ \\
Never & 292 & $(58.75)$ & 19 & $(6.51)$ & $3.96-9.97$ & \\
\hline Alcohol, drugs and other risk factors & & & & & & & \\
Smoker & 56 & ( & 5 & $(8.93)$ & $2.96-19.62$ & 0.85 & $0.371^{*}$ \\
Alcohol use & 209 & $(42.05)$ & 6 & $(2.87)$ & $1.06-6.14$ & - & - \\
Illegal drugs use & 21 & $(4.23)$ & 1 & $(4.76)$ & $0.12-23.82$ & 0.59 & $0.395^{*}$ \\
Blood transfusion & 43 & $(8.88)$ & 6 & $(13.95)$ & $5.30-27.93$ & 5.20 & $0.036^{*}$ \\
Tattoo & 89 & $(17.91)$ & 2 & $(2.25)$ & $0.27-7.88$ & 2.74 & $\mathbf{0 . 1 3 8 ^ { * }}$ \\
Piercing & 55 & $(11.07)$ & 1 & $(1.82)$ & $0.00-9.72$ & 1.94 & $0.233^{*}$ \\
Shares syringe/needle & 6 & $(1.21)$ & 0 & $(0)$ & 0 & - & - \\
Without sterilized tools & 244 & $(49.09)$ & 0 & $(0)$ & 0 & - \\
Surgery last year & 55 & $(11.07)$ & 3 & $(5.45)$ & $1.14-15.12$ & - \\
Hepatitis B vaccine & 282 & $(72.12)$ & 14 & $(4.96)$ & $2.74-8.19$ & - \\
\hline
\end{tabular}

Positive Serology

Elisa - Treponemic Test $\quad 36 \quad(7.24)$

VDRL - Non-treponemic Test $30 \quad(6.04)$

VDRL Titration

$\begin{array}{lcc}1 / 2 \text { to } 1 / 4 & 24 & (82.77) \\ >1 / 8 & 6 & (17.23)\end{array}$

STI = Sexually-Transmitted Infections; HIV = Human Immunodeficiency Virus; ELISA = Enzyme-Linked Immunosorbent Assay; $\operatorname{VDRL}=$ Venereal Disease Research Laboratory. ${ }^{*}$ Exact Fisher Test. Highlighted $p \leq 0.2$. 
Table 2 - Bivariate analysis and multivariate Poisson regression analysis on the prevalence ratio of syphilis among women attended in the primary health care system.

\begin{tabular}{|c|c|c|c|c|c|c|}
\hline Variables & PR & IC $95 \%$ & $p$-value & PR adjusted & IC $95 \%$ & $\mathrm{p}$-value \\
\hline \multicolumn{7}{|l|}{ Education } \\
\hline High school and graduation & 0.957 & $0.918-0.998$ & 0.039 & 0.940 & $0.902-0.980$ & 0.004 \\
\hline Income less than 2 minimal wages & 0.940 & $0.918-0.980$ & 0.002 & 0.958 & $0.924-0.993$ & 0.019 \\
\hline \multicolumn{7}{|l|}{ Sexual history } \\
\hline Multiple sexual partners & 1.083 & $1.001-1.171$ & 0.047 & 0.937 & $0.866-1.014$ & 0.106 \\
\hline Genital ulcer disease & 0.917 & $0.832-1.012$ & 0.085 & - & - & - \\
\hline
\end{tabular}

$\mathrm{PR}=$ Prevalence ratio. Highlights $\mathrm{p} \leq 0.05$.

The prevalence of $T$. pallidum infection among women was $6.04 \%$ [95\% CI: 4.11-8.50]. The highest prevalence rates were found in women living in the Joquei neighborhood $10.77 \%$ [95\% CI: 4.44-20.94], illiterate women $13.4 \%$ [95\% CI: 2.78-33.59], black women $10.53 \%$ [95\% CI: 2.94-24.80] and without a stable sexual partner $11.96 \%$ [95\% CI: 6.12-20.39]. Regarding behavioral factors, the highest prevalence rates were found among women that had history of STI (16.22\% [95\% CI: 6.19-32.01]), genital ulcers (12.90\% [95\% CI: 5.74-23.85]), without a stable sexual partner and referring irregular use of condoms during sexual intercourse (24.24\% [95\% CI: $11.09-42.26$ ] and who had a blood transfusion (13.95\% [95\% CI: 5.30-27.93]) (Table 1). All cases were reported to healthcare services to provide appropriate treatment.

The bivariate analysis showed that women with multiple sexual partners $\left(\chi^{2}: 6.44[\mathrm{p}=0.014]\right)$, income less 2 minimum wages $\left(\chi^{2}: 15.93[\mathrm{p}=0.003]\right)$, who did not have high school $\left(\chi^{2}: 12.64[\mathrm{p}=0.005]\right)$, and who reported history of STIs $\left(\chi^{2}: 7.30\right.$ [p=0.018] $)$ are more likely to have syphilis (Table 1). In the bivariate Poisson regression model, the prevalence was higher among women who did not have high school (PR 0.95 [95\% CI: 0.91-0.99]), with income less 2 minimal wages (PR 0.94 [95\% CI: 0.91-0.98]), and with multiple sexual partners (PR 1.08 [95\% CI: 1.01-1.17]). In the multivariate analysis, the highest prevalence ratio was observed in women with income less 2 minimal wages (PR: 0.96 [95\% CI: 0.85-0.97]), and who did not have high school (PR: 0.94 [95\% CI: 0.90-0.98]). (Table 2).

\section{DISCUSSION}

In the present study, we described the prevalence and the factors associated with $T$. pallidum infection among women. The number of occurrences was higher than the global prevalence, which estimated a prevalence of $0.5 \%$ among women aged 15-49 years. The prevalence rate in our study is similar to the one found in women in vulnerable situations $^{12,13}$. This high prevalence among women is a concern since, in an eventual pregnancy, T. pallidum can infect the fetus and lead to adverse outcomes when untreated, such as abortion and risk to the women's health and the child's neuropsychomotor development ${ }^{14,15}$. Thus, the public health policies need to be strengthened according to the reality of these populations in an attempt to reduce the number of cases of syphilis.

We identified that $63.89 \%$ of the participants with syphilis had multiple sexual partners and $80 \%$ reported occasional condom use. These behaviors could have facilitated T. pallidum transmission. Moreover, the high rates of syphilis could be a potential risk for the spread of other STIs, including HIV, during unprotected $\operatorname{sex}^{16}$. The chance of transmitting HIV is five-fold increased if either partner has an ulcerative STI like syphilis ${ }^{10,11}$. The lesions of this pathological condition contain an abundance of lymphocytes, which makes the infiltration of HIV more recurrent. Furthermore, the immunosuppression caused by HIV may favor the evasion of the host defense mechanisms by $T$. pallidum ${ }^{16,17}$. A positive status for $T$. pallidum in patients with a previous history of STI may be associated with unprotected sex. An additional element that can increase syphilis rates may be the presence of genital ulcers. T. pallidum transmission rate was estimated to be $20 \%$ to $30 \%$ higher per sexual act. Besides, multiple partners increase the likelihood of transmission and dissemination of this pathogen ${ }^{17}$. It is important to note that condoms are not as effective to prevent infections that are transmitted through lesions, if it does not cover the wound ${ }^{18}$. Thus, the presence of ulcers can facilitate the occurrence of syphilis and other infectious diseases ${ }^{19}$.

Since several factors were associated with T. pallidum among women, it is likely that multiple approaches could contribute for the reduction of syphilis rates. An alternative to reduce the prevalence of syphilis would be to concentrate efforts for the follow-up of positive cases and the effectiveness of the treatment, as well as the sexual partners. 
As widely known, diagnostic has a central role in guiding the procedure. In some cases, a specific stage of syphilis can be asymptomatic ${ }^{16}$. Thus, screening programs could be an essential preventive approach. Studies have shown that regular screening (every 3-6 months) among groups at high risk to acquire STI, can contribute for reducing the incidence of syphilis ${ }^{20}$.

We showed that socioeconomic variables, such as low income and poor educational levels were frequent in this population, the same situation reported in the USA, China and Argentina ${ }^{21-23}$. In our study, the prevalence of syphilis was higher in women with an income of less than 2 minimal wages (96\%) who did not have high school (94\%). These data may indicate a relationship between socioeconomic factors and the prevalence of syphilis in this population. In addition, the prevalence of syphilis was different among the evaluated primary health care units. The Joquei primary health care unit located on the outskirts of the city showed a higher positive rate $(10.77 \%)$ and $70.76 \%$ had only a basic educational level. This may indicate inequalities in self-care, as well as difficulties to access and continue to seek treatment in health services. Public health has an essential role in disease prevention. However, budget cuts over the last several years may have hampered the STI preventive measures, such as a decrease in syphilis screening. Furthermore, Brazil suffered from a shortage of Benzathine penicillin G, a drug used in the syphilis treatment ${ }^{24}$. Thus, these factors may also have contributed to the high prevalence of syphilis among Brazilian women. All these factors have a direct impact on the quality of services provided by primary health care units that should monitor the health of the population, as well as subsidizing educational measures that help to reduce the number of syphilis cases.

There were some limitations in this study. Firstly, it was a prospective study in one Brazilian city. Secondly, it was a convenience sample for women who sought primary health care units. This is a selection bias and may have interfered with the high prevalence found. In addition, despite the sample size being sufficient to infer the prevalence of syphilis, it was inadequate to perform stratified analyses of variables. Besides the limitations, our study provides insights on the prevalence of syphilis in Brazilian women.

The high prevalence of T. pallidum infection, especially in a scenario of heavy border traffic, as is the case in Dourados, has evidenced the need for interventions to reduce sexual behaviors that are associated with an increased risk of STIs in women. Thus, our study reinforces the importance of active surveillance in the primary health care through the extensive testing of patients and their sexual partners, seeking to detect symptomatic and asymptomatic syphilis cases, promoting the adequate treatment promptly. In addition, interventions that encourage safe sexual practices could reduce T. pallidum transmission, as well as eventual congenital infections.

\section{ACKNOWLEDGMENTS}

We are grateful to the Secretary of Health from Dourados, Mato Grosso do Sul State, and the women who participated in our study, without whom this research could have been performed. Our appreciation is also extended to the staff of the GPBMM/UFGD study group for their support.

\section{FUNDING}

This study has received funding from the Conselho Nacional de Desenvolvimento Científico e Tecnológico (CNPQ, grant No 40245/2018-4), Fundação de Apoio ao Desenvolvimento do Ensino, Ciência e Tecnologia do Estado do Mato Grosso do Sul (FUNDECT, grants N ${ }^{\circ}$ 092/2015 and 041/2017), Coordenação de Aperfeiçoamento de Pessoal de Nivel Superior (CAPES) and Universidade Federal da Grande Dourados (UFGD). KES received a scholarship from CAPES. ECS, LGO and JHFSQ from FUNDECT. The sponsors had no role in the collection, analysis and interpretation of the data nor the writing of the manuscript.

\section{REFERENCES}

1. Puccio JA, Cannon A, Derasari K, Friend R. Resurgence of syphilis. Adv Pediatr. 2019;66:231-44.

2. Hussain SA, Vaidya R. Congenital syphilis. Treasure Island: StatPearls Publishing; 2019.

3. Forrestel AK, Kovarik CL, Katz KA. Sexually acquired syphilis: historical aspects, microbiology, epidemiology, and clinical manifestations. J Am Acad Dermatol. 2020;82:1-14.

4. Forrestel AK, Kovarik CL, Katz KA. Sexually acquired syphilis: laboratory diagnosis, management, and prevention. J Am Acad Dermatol. 2020;82:17-28.

5. Rowley J, Vander Hoorn S, Korenromp E, Low N, Unemo M, Abu-Raddad LJ, et al. Chlamydia, gonorrhoea, trichomoniasis and syphilis: global prevalence and incidence estimates, 2016. Bull World Health Organ. 2019;97:548-62P.

6. Kularatne RS, Niit R, Rowley J, Kufa-Chakezha T, Peters RP, Taylor MM, et al. Adult gonorrhea, chlamydia and syphilis prevalence, incidence, treatment, and syndromic case reporting in South Africa: estimates using the Spectrum-STI model, 1990-2017. PLoS One. 2018;13:e0205863.

7. Santos MM, Lopes AK, Roncalli AG, Lima KC. Trends of syphilis in Brazil: a growth portrait of the treponemic epidemic. PLoS One. 2020;15:e0231029. 
8. Brasil. Ministério da Saúde. Secretaria de Vigilância em Saúde. Sífilis 2019. Bol Epidemiol. 2019;N Esp:1-43. [cited 2020 Nov 20]. Available from: http://www.aids.gov.br/pt-br/pub/2019/ boletim-epidemiologico-sifilis-2019

9. Brasil. Ministério da Saúde. Agenda de ações estratégicas para redução da sífilis no Brasil. Brasília: Ministério da Saúde; 2017. [cited 2020 Nov 20]. Available from: http://www.aids.gov.br/ pt-br/pub/2017/agenda-de-acoes-estrategicas-para-reducaoda-sifilis-no-brasil

10. World Health Organization. Global health sector strategy on sexually transmitted infections, 2016-2021. Geneva: WHO 2016. [cited 2020 Nov 20]. Available from: http://www.who. int/reproductivehealth/publications/rtis/ghss-stis/en/

11. Instituto Brasileiro de Geografia e Estatística. Estimativas da população. [cited 2020 Nov 20]. Available from: https://www. ibge.gov.br/estatisticas/sociais/populacao/9103-estimativasde-populacao.html?=\&t=downloads

12. Newman L, Kamb M, Hawkes S, Gomez G, Say L, Seuc A, et al. Global estimates of syphilis in pregnancy and associated adverse outcomes: analysis of multinational antenatal surveillance data. PLoS Med. 2013;10:e1001396.

13. Newman L, Rowley J, Hoorn SV, Wijesooriya NS, Unemo M, Low N, et al. Global estimates of the prevalence and incidence of four curable sexually transmitted infections in 2012 based on systematic review and global reporting. PLoS One. 2015;10:e0143304.

14. Benedetti KC, Ribeiro AD, Queiroz JH, Melo AB, Batista RB, Delgado FM, et al. High prevalence of syphilis and inadequate prenatal care in Brazilian pregnant women: a cross-sectional study. Am J Trop Med Hyg. 2019;101:761-6.

15. World Health Organization. WHO guidelines for the treatment of Treponema pallidum (syphilis). Geneva: WHO; 2016 [cited 2020 Nov 20]. Available from: https://apps.who.int/iris/ bitstream/handle/10665/249572/9789241549806-eng.pdf
16. Peeling RW, Mabey D, Kamb ML, Chen XS, Radolf JD, Benzaken AS. Syphilis. Nat Rev Dis Primers. 2017;3:17073.

17. Schmidt R, Carson PJ, Jansen RJ. Resurgence of syphilis in the United States: an assessment of contributing factors. Infect Dis (Auckl). 2019;12:1178633719883282.

18. Stoltey JE, Cohen SE. Syphilis transmission: a review of the current evidence. Sex Health. 2015;12:103-9.

19. Long FQ, Wang QQ, Jiang J, Zhang JP, Shang SX. Acquired secondary syphilis in preschool children by nonsexual close contact. Sex Transm Dis. 2012;39:588-90.

20. Tuite AR, Fisman DN, Mishra S. Screen more or screen more often? Using mathematical models to inform syphilis control strategies. BMC Public Health. 2013;13:606.

21. Parker LA, Deschutter EJ, Bornay-Llinares FJ, Hernandez-Aguado I, Silva G, Piragine RC, et al. Clinical and socioeconomic determinants of congenital syphilis in Posadas, Argentina. Int J Infect Dis. 2012;16:e256-61.

22. Umapathi KK, Thavamani A, Chotikanatis K. Incidence trends, risk factors, mortality and healthcare utilization in congenital syphilis-related hospitalizations in the United States: a nationwide population analysis. Pediatr Infect Dis J. 2019;38:1126-30.

23. Qin JB, Feng TJ, Yang TB, Hong FC, Lan LN, Zhang CL, et al. Risk factors for congenital syphilis and adverse pregnancy outcomes in offspring of women with syphilis in Shenzhen, China: a prospective nested case-control study. Sex Transm Dis. 2014;41:13-23.

24. Nurse-Findlay S, Taylor MM, Savage M, Mello MB, Saliyou $\mathrm{S}$, Lavayen $\mathrm{M}$, et al. Shortages of benzathine penicillin for prevention of mother-to-child transmission of syphilis: an evaluation from multi-country surveys and stakeholder interviews. PLoS Med. 2017;14:e1002473. 